\title{
Cavitation Erosion Resistance of Laser Beam Nitride Layers of X5CrNi18-10 Stainless Steel
}

\author{
ILARE BORDEASU1*, CORNELIA LAURA SALCIANU1*, MIRCEA OCTAVIAN POPOVICIU², ION MITELEA ${ }^{1}$ \\ ${ }^{1}$ Politechnica University of Timisoara, 1 Mihai Viteazul Blvd., 300222, Timisoara, Romania \\ ${ }^{2}$ Academy of Romanian Scientists, Timisoara Branch, 1 Mihai Viteazul Blvd., 300222, Timisoara, Romania
}

\begin{abstract}
The use of nitration in technical applications, as thermochemical treatment, regardless of the used method (ionic, gas or laser beam nitration) is realized to obtain a nitrogen rich layer, which increase the resistance to shock or abrasion, as a result of the high hardness obtained. All the previous cavitation researches showed that hardness is an important mechanical properties, for cavitation erosion resistance increase. The present paper show some results regarding the cavitation erosion behavior of laser beam nitrated layers. As basic material was used the austenitic stainless steel X5CrNi18-10. This material is frequently used for manufacturing details subjected to cavitation, such as valves, drawers of hydraulic distribution and regulation devices, or the retaining ring for butterfly valves. There were used three power regimes of the laser beams: $120 \mathrm{~W}, 180 \mathrm{~W}$ and $240 \mathrm{~W}$. To obtain cavitation erosion was used the standard device with piezo-ceramic crystals of Timisoara Polytechnic University Cavitation Laboratory. The cavitation erosion comparisons, both with the basic material subjected only to the common thermochemical treatments and with the laboratory cavitation standard steel (OH12NDL), show that the nitrated surfaces presents increased cavitation erosion behavior, the principal factor being the important hardness increase of the nitrated layer. We mention also, that for higher laser beam powers the thickness of the nitrated layer increases. All the images obtained at the end of tests show that the cavitation exposure was stopped before overtaking the nitrated layer. So, all our results concern only the hardened layers.
\end{abstract}

Keywords: cavitation erosion resistance, laser beam nitride layers, stainless steel, cavitation erosion characteristic curves, hardness

The use of performant measuring and shooting equipment for tracking the evolution of cavitation bubbles show that the damages suffered by the exposed solid surfaces is caused by shocks with very high pressure (with the magnitude order of thousand Pascal) [1-10], inducing in the superficial layers tensions greater than those of the inter and trans crystalline bounds. The majority of the undertaken studies and researches works regarding the material destruction show that the hardness value is the principal factor responsible for the erosion degree. The researches and studies undertaken by Hammitt and other $[1,9,10]$, with regard of the hardness effectupon the surface resistance, show that the mean depth erosion (MDE) decreases with the value of hardness. Based on these results, the researchers begun to use the increase of the hardness of the exposed area, but without bringing them into the breakable domain. An excellent technique for this purpose is nitration.

The laser beam nitration was increasingly used in the last time, [11-14] due to the fact that the striated and hard layers having a great content of nitrogen does not change the chemical composition of the basic structure. The nitrated layer has an excellentadherence with the sublayer and his depth depend significantly to the laser beam power. The striations resulting from the displacement of the laser beam can be reduced through grinding or polishing, with the condition that the depth of the nitrated layer to remain thick enough. The most numerous application of nitration are for the pieces with a simple geometry and reduced dimensions which must not have great fatigue resistance but must show an improved behavior for shock absorption, as in the case of those produced by a fluid working in cavitation.

\section{Experimental part}

Researched material

Nitrating procedure

The researched material is the stainless austenitic steel X5CrNi18-10, with good welding ability and used for details requiring good corrosion resistance in fresh water, see water, nitric acid, sulfuric acid and other such aggressive media [15-17]. In conformity with the Schäffler diagram [15] it is composed by $88 \%$ austenite and $12 \% \mathrm{~d}$ ferrite.

The chemical composition and mechanical properties, specified by the producer $[15,18]$ and verified in the laboratories of Timisoara Polytechnic University are: 0.046 $\% \mathrm{C}, 17.95 \% \mathrm{Cr}, 8.11 \% \mathrm{Ni}, 1.46 \% \mathrm{Mn}, 0.89 \% \mathrm{Si}, 0.27 \% \mathrm{Cu}$, $0.16 \% \mathrm{~W}, 0.024 \% \mathrm{P}, 0.019 \% \mathrm{~S}, 0.09 \% \mathrm{~N}$, the remainder being $\mathrm{Fe} ; \mathrm{R}_{\mathrm{m}}=550 \mathrm{MPa}, \mathrm{R}_{\mathrm{p} 0.2}=195 \mathrm{MPa}$, Brinell hardness $\mathrm{HB}=183 \mathrm{dan} / \mathrm{mm}^{2}$ (approximate $\mathrm{HV}=192 \mathrm{daN} / \mathrm{mm}^{2}$ ), elongation at break $A_{5}=45 \%$.

For common parts, this material is used after quenching at $1050^{\circ} \mathrm{C}$, with a maintenance duration of $25 \mathrm{~min}$ and with sudden cooling in water. The mean hardness of the superficial layer, measured after quenching is198 HV1. This parameter was carefully measured because in conformity with the studies of Garcia and other [9] but also taking into account the older studies of our laboratory [19-22], hardness is the principal factor influencing the cavitation erosion resistance. The chosen material for researches was adopted, taking into account his large use in various applications such as the construction of the valves working in cavitation flows with fresh or salt water. In these application in addition to the corrosive effect, cavitation is also present [15, 17, 19, 22, 23].

The laser beam nitration, as an industrial process for treating the surfaces exposed for different stresses is more

*email: ilare.bordeasu@upt.ro, ilarica59@gmail.com, Phone: 0723650248; salcianu.laura@yahoo.com, Phone: 0740159673 
and more common because is very easy to be applied and in the same time it realize good functioning layers without substantially influencing the basic material $[12,14,15]$. This advantage is given by the nitration with a transversal speed of about $100 \mathrm{~mm} / \mathrm{s}$ [12], achieving a strong dissolution of nitrogen and so forming a hard layer. For the nitration of cavitation erosion samples was used the Trumpf HL 124P LCU device equipped with programmable pulsed laser Nd-YAG, (fig.1), found in the endowment of

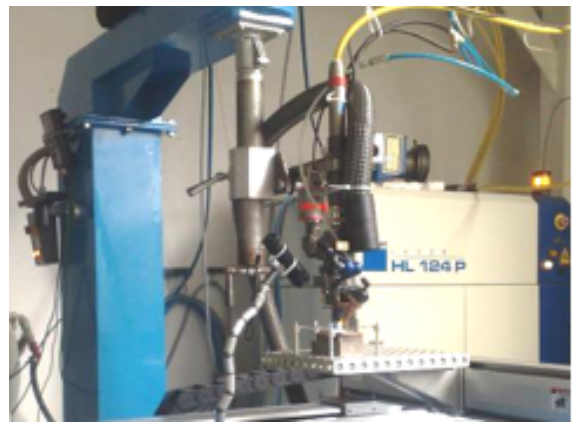

Fig. 1. HL 124P LCU device

the Timisoara National Institute for Researches in the Field of Welding and Material Testing.

The nitration procedure consisted in scanning the specimen surfaces with a laser beam, in a pure nitrogen atmosphere. The nitrogen flow was $33 \mathrm{l} / \mathrm{min}$. The laser beam parameters were: the impulse frequency $10 \mathrm{~Hz}$ and three different impulse powers: $120 \mathrm{~W}, 180 \mathrm{~W}, 240 \mathrm{~W}$ with an exposure time of $8 \mathrm{~ms}$.

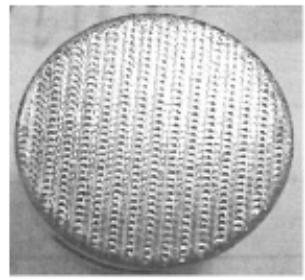

$\mathrm{P}_{\text {impuls }}=120 \mathrm{~W}$

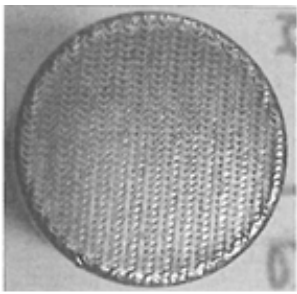

$\mathrm{P}_{\text {impuls }}=240 \mathrm{~W}$

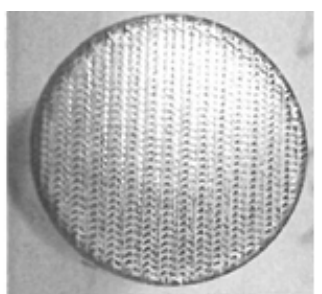

$\mathrm{P}_{\text {impuls }}=180 \mathrm{~W}$

Fig.2. Photos of the nitrate surfaces
In figure 2 are presented the images of the laser nitrated surfaces for each power impulse, the images being realized with a Canon Power Shot photographic device.

The images in figure 2 show the peculiar form of the nitrated layer, with waves formed by the movement of the laser beam displacement. The wave fines increase with the impulse power but the important fact was the influence upon the cavitation erosion resistance. Realized in a transversal section, in conformity with the figure 3 scheme, the measurements show a gradual reduction of the hardness in the $55 \mathrm{~mm}$ thick nitrated layer from approximate $(550 \ldots 600)$ HV0.3 measured at the layer

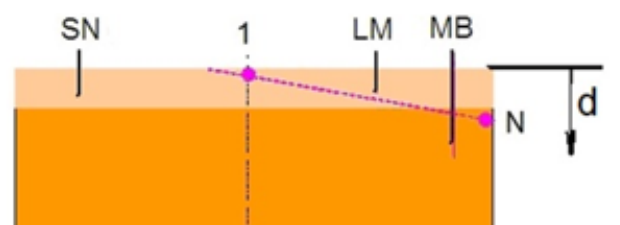

Fig. 3. Nitrated layers hardness [15]

SN - Nitrate layer MB - Base materia

LM - Measuring line

1... $\mathrm{N}$ - Measuring number

d - Measuring distance

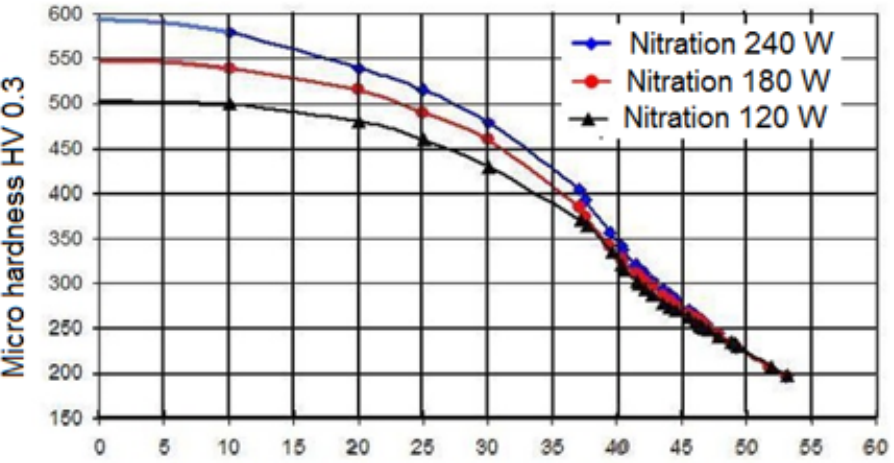

Measured distance from surface to the interior, $d[\mu \mathrm{m}]$

Fig. 4. Hardness variation in the section of laser nitrated surface [15]

surface to approximate 200 HV0.3 in the area near the basic material figure 4.

\section{Results and discussions}

The cavitation erosion resistance of different samples was obtained by using a Standard Vibratory Device ASTM G32-2010, with piezo ceramic crystals, in the Cavitation Laboratory of Timisoara Polytechnic University [24]. In conformity with the standard requirements [25] and the laboratory habits, for each power regime were tested three specimens. Before the tests the exposed surface was polished at a roughness of $\mathrm{Ra}=0.08 \mathrm{~mm}$, the thickness of the deposited layer remaining between 142 and $210 \mu \mathrm{m}$ (fig. 12). Also the cylindrical surface of the nitrated layer was turned with a lathe at the sample diameter $(15.8 \mathrm{~mm})$, in order to eliminate the irregularities resulting from the melting with the laser beam. The procedures for preparing,

\section{Polished surface after nitration \\ (before the beginning of the cavitation exposure)}

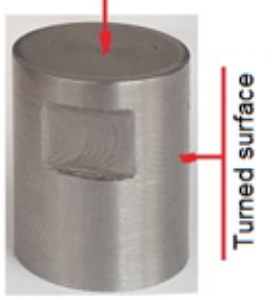

Fig.5. Photo of the specimen prepared for cavitation erosion testing

testing and data recording were the standard ones, used in our laboratory $[6,8,12,14,15,17,19,20,24]$. In figure 5 it can be seen a photograph of the specimen.

The behavior of the laser treated layers at cavitation erosion are presented in the figure 6-8. There are given both the evolution of the mean depth erosion $\operatorname{MDE}(t)$ and the mean depth erosion rate $\operatorname{MDER}(\mathrm{t})$. Examining the evolution of the curves $\operatorname{MDE}(t)$ and $M D E R(t)$ as well as the 


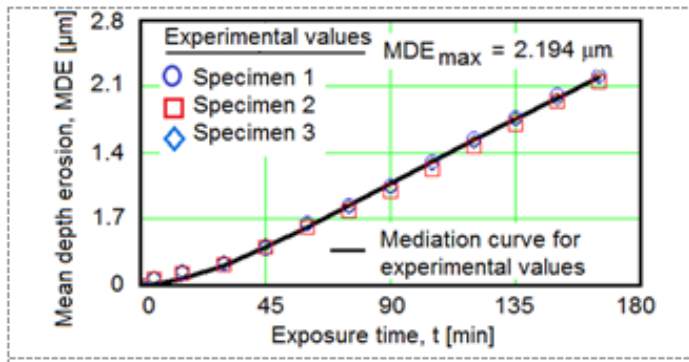

a)

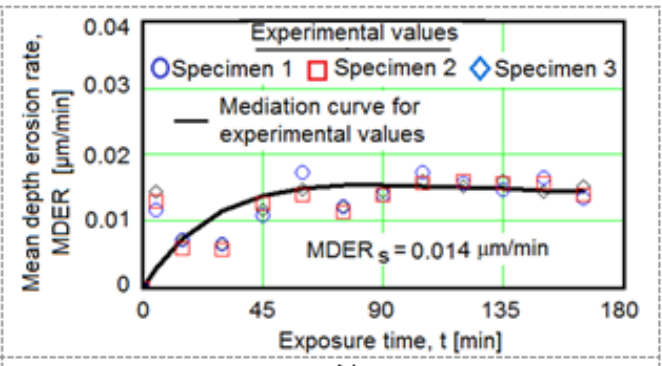

b)

a) Mean depth erosion against cavitation exposure time; b) Mean depth erosion rate against cavitation exposure time

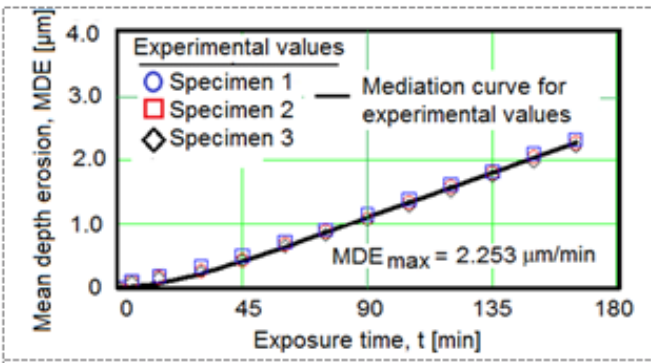

a)

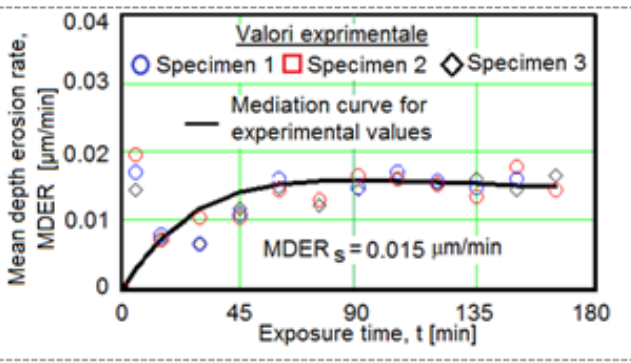

b)

Fig. 7. Cavitation erosion characteristic curves (180 W)

a) Mean depth erosion against cavitation exposure time; b) Mean depth erosion rate against cavitation exposure time

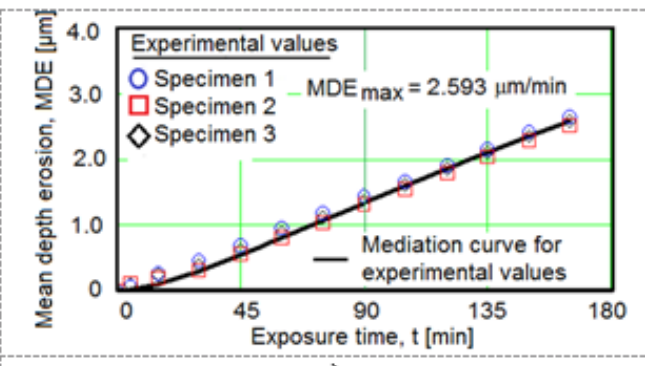

a)

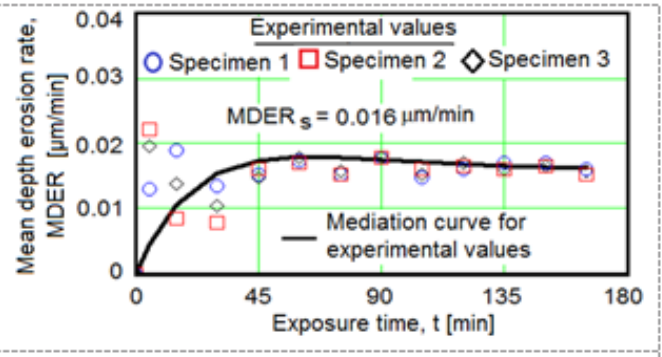

b)

a) Mean depth erosion against cavitation exposure time ; b) Mean depth erosion rate against cavitation exposure time

scatter of the experimental points, the following conclusions can be drawn:

-in the first 15-30 min of testing, the nitrated surfaces for all three specimens and for all the treatment regimes, have a different behavior and after the values of MDER parameter (fig. 6b, 7b, 8b), it can be created a false impression that the nitrated layer has at the begining a week behavior at cavitation erosion. Taking into account the experience of over 70 years of testing [22] this interval must not be considered as characteristic one for the resistance of the material. Upon us, this behavior is the result of the existence of some week components such as oxides and poorly adherent crusts, which were not eliminated in the process of cleaning/washing procedures and are rapid eliminated at the beginning of the tests;

-all three specimens of the same material show similar behavior, expressed by the superposition of the measured points on the interval $45 . . .165$ min of cavitation exposure;

-the measured values are characteristic for materials with excellent cavitation erosion resistance [22]; the conclusion is confirmed also by the linear evolution of the curves $\operatorname{MDE}(t)$, on the interval $45-165 \mathrm{~min}$ and by the tendency of the curve $\operatorname{MDER}(\mathrm{t})$ to be stable at the maximum value of the erosion velocity;

-the reduced scatter of the experimental values (after minute 45), around the mediation curves are the result of the uniform distribution of the hardness in the entire area of the nitrated surface, as a result of the accuracy of the nitration procedure respecting the working parameters (impulse power, speed of beam movement, impulse duration); this conclusion is confirmed also by the photo images of the surfaces at the test end, (fig. 9);

-comparing the three different procedures, the surfaces nitrated with an impulse power of $240 \mathrm{~W}$ give the best behavior to cavitation erosion, presenting the most reduced scatter and even the superposition of all measured values in the 45-165 minute interval of cavitation exposure, (fig. $8 b)$.

The images of figure 9 , correlated with the maximum

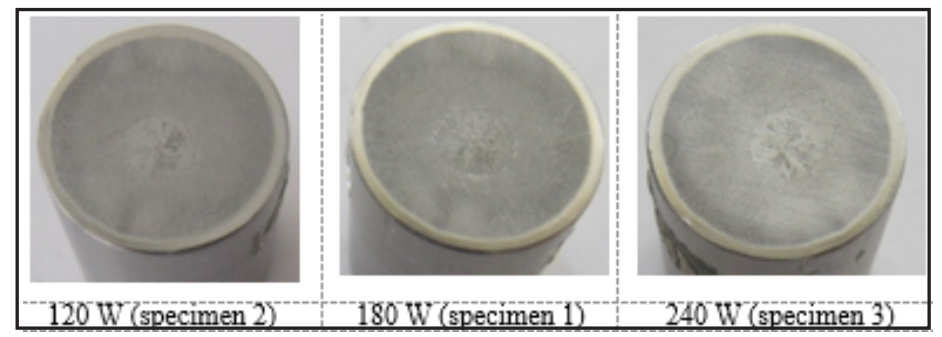

Fig. 9. Images of the eroded nitrated layer after $165 \mathrm{~min}$ of exposure to cavitation 


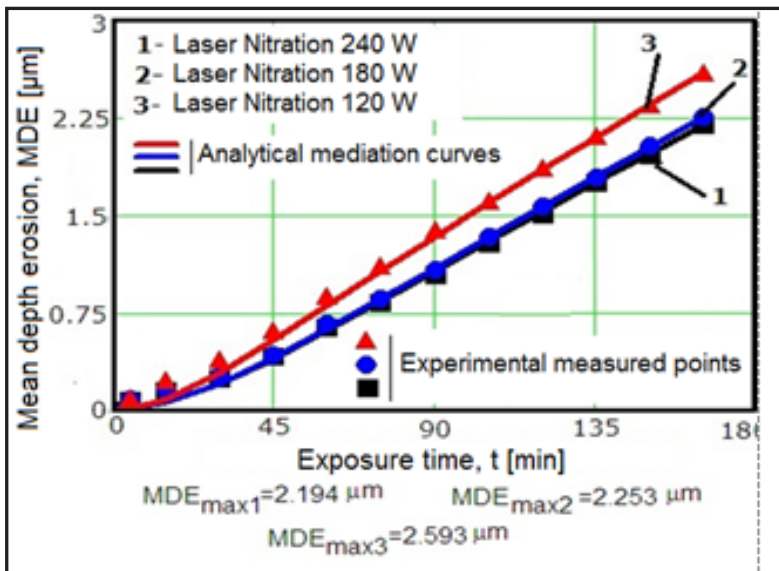

a)

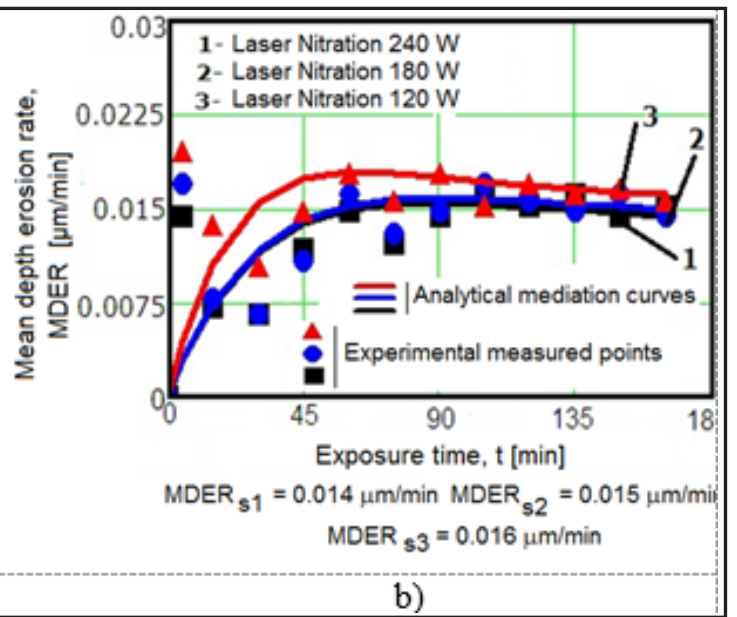

b)

Fig.10. Comparisons of the characteristic cavitation erosion curves:

a) Mean depth erosion against cavitation exposure time ; b)Mean depth erosion rate against cavitation exposure time

depth values of the erosion from figure $6-8$, show that the penetration of cavitation erosion affect in a small measure the nitrated layer remained after polishing. We appreciate that this reduced depth of the erosion is the result of the great hardness of the treated layer $(550 . . .600) \mathrm{HV}_{0.3^{\prime}}$ (fig. 4).

To identify which one of the three nitration regimes give the greatest resistance to cavitation erosion, in figure 10 there are made comparisons between the curves $\operatorname{MDE}(t)$ and $\operatorname{MDER}(t)$. The experimental values presented in figure 10 for MDE and MDER are means for the three tested specimens.

The mediation curves shape in figure 10 show that the differences between the evolutions of the erosion depth $\operatorname{MDE}(t)$ but also those of mean depth erosion rates $\operatorname{MDER}(t)$, for the specimens nitrated with laser beams at powers of $120 \mathrm{~W}$ and $180 \mathrm{~W}$ are extremely small. The use of laser beams with a power of $240 \mathrm{~W}$ increase substantially the cavitation erosion resistance. Taking as comparison element only the final measured values of the cavitation erosion resistance, we obtain the following conclusions:

- the value $\mathrm{MDE}_{\text {max }}$ is approximately with $18 \%$ greater and the value MDER ${ }_{s}^{\text {max }}$ with approximately $14 \%$ greater for the power $240 \mathrm{~W}$ in comparison with the use of power 120 W,

\section{and}

- the value $M D E_{\text {max }}$ is approximately with $15 \%$ greater and the value MDER ${ }_{s}$ with approximately $7 \%$ greater; for the power $240 \mathrm{~W}$ in comparison with the use of pow er 180 W.
Evidently, those modifications appear as a result of the hardness increases (fig. 4) of the nitrated surfaces (approx. $600 \mathrm{HV}_{03}$ for the laser beam power of $240 \mathrm{~W}$, approx. 550 $\mathrm{HV}_{03}$ for the laser power of $180 \mathrm{~W}$ and approx. $500 \mathrm{HV}_{0.3^{\prime}}$ for the laser power of $120 \mathrm{~W}$ ).

It can be seen that the increase of the cavitation erosion resistance (regardless of the chosen parameter $\mathrm{MDE}_{\text {mat }}$ or $M D R$ ) is not directly proportional with the increase of the laser beam power (of about $100 \%$ respectively $33 \%$, taking as reference the laser beam power of $120 \mathrm{~W}$ ).

For the evaluation of the cavitation erosion increase realized with the steel X5CrNi18-10 nitrated with laser beams, in figure 11 are made comparisons with both: the same steel in quenched state and the stainless steel $\mathrm{OH} 12$ NDL considered with good cavitation erosion resistance and taken as standard steel in our Cavitation Erosion Laboratory [, 14, 15, 17, 22, 24]. As comparison parameters were taken $\mathrm{MDE}_{\text {max }}$ and $\mathrm{R}_{\mathrm{cav}}=1 / \mathrm{MDER}_{\mathrm{s}}$.

Regardless of the used parameter, the data in figure 11 histogram confirm that the laser beam nitrated surfaces, regardless of the power used ( $120 \mathrm{~W}, 180 \mathrm{~W}$ or $240 \mathrm{~W}$ ) receive a very high cavitation erosion resistance as the result of the great hardness of the nitrated surface. The increases in comparison with the standard cavitation erosion steel $\mathrm{OH} 12 \mathrm{NDL}$ is:

- after the values of the cavitation erosion resistance $R_{c a v}$ : through nitration with the power $240 \mathrm{~W}$ is approximately 12 times greater; through nitration with the power $180 \mathrm{~W}$ is approximately 11 times greater; through nitration with the power $120 \mathrm{~W}$ is approximately 10 times greater;

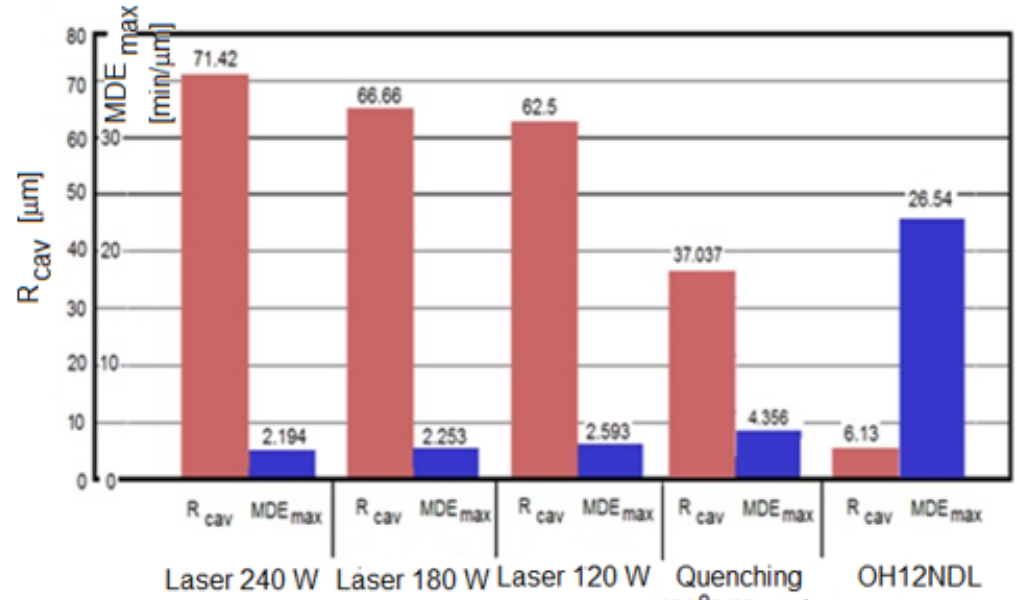

$1050^{\circ} \mathrm{C} / 25 \mathrm{~min} /$ water
Fig. 11. Appreciation of cavitation erosion increase by comparisons between the laser treated samples with the same steel only quenched and the standard steel OH12NDL 


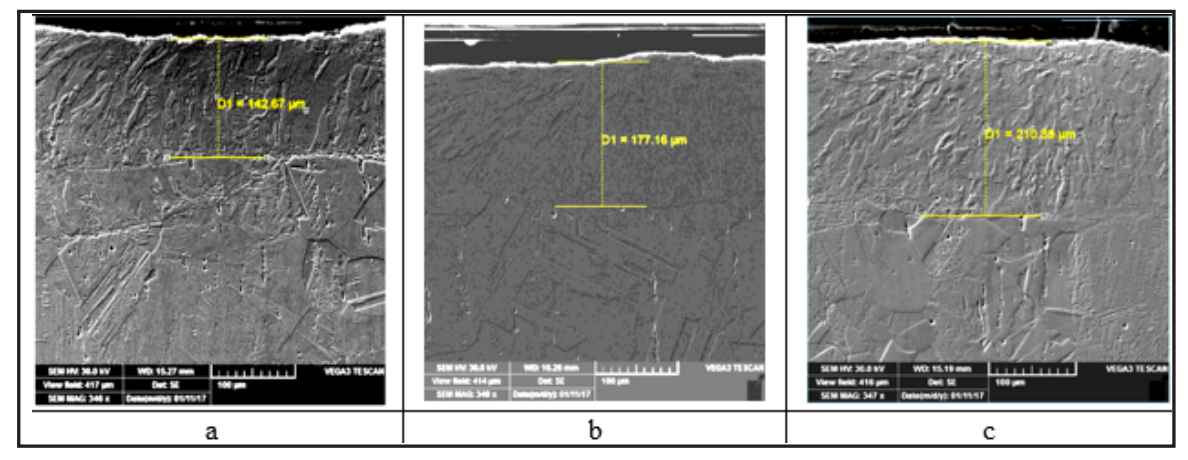

Fig. 12. Images showing the nitrated layer and the base material

a) $P=120 \mathrm{~W}$; b) $P=180 \mathrm{~W}$; c) $P=240 \mathrm{~W}$

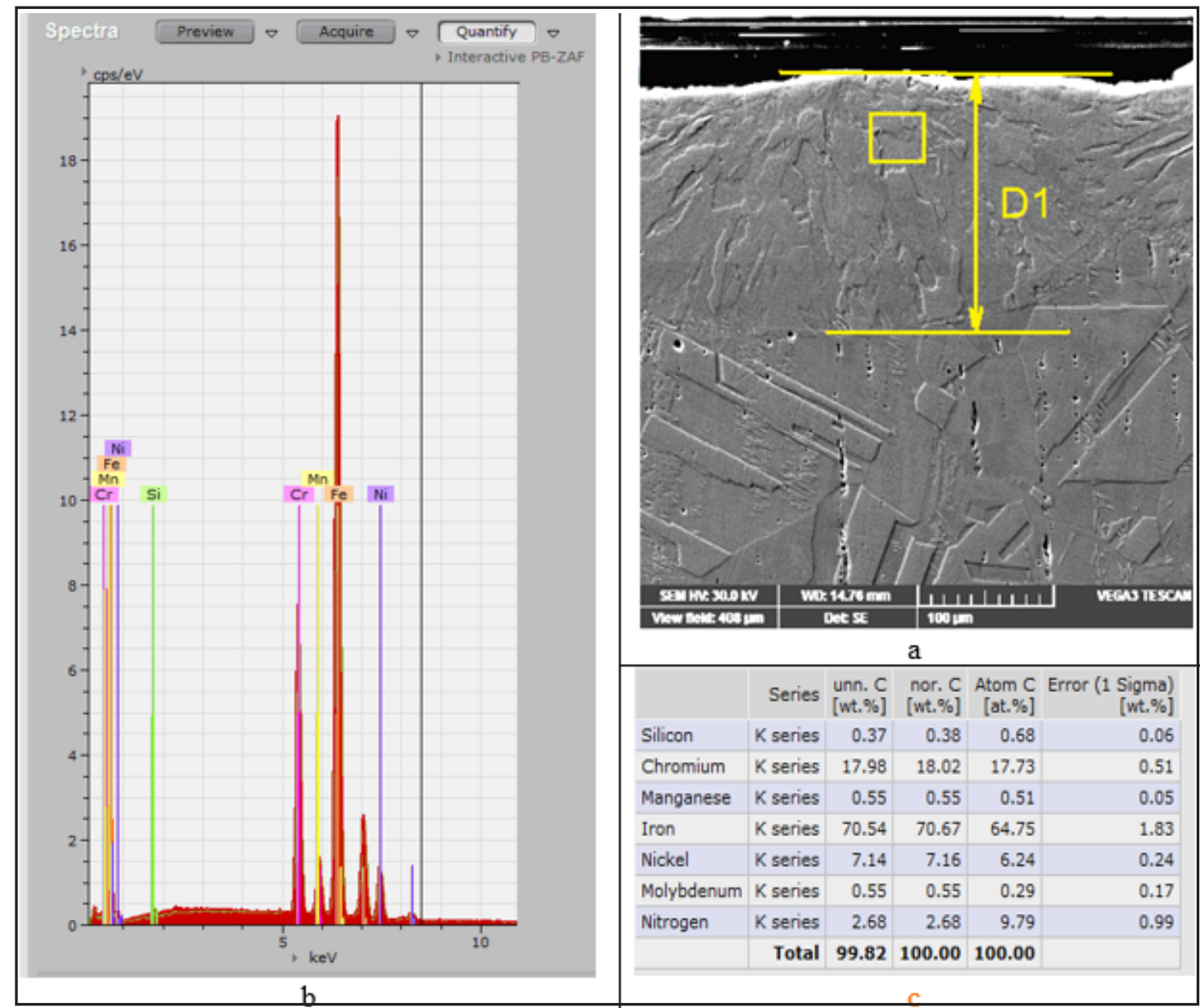

Fig. 13. Spectrographic analyze of the nitrated layer subjected to a laser beam having $240 \mathrm{~W}$ impulse power a) analyzed zone; b) spectrograms c) chemical composition

- after the values of mean depth erosion $M D E_{\text {max }^{\prime}}$ obtained in 165 min of explosion: through laser nitration with $240 \mathrm{~W}$ is approximately 12 greater; through laser nitration with $180 \mathrm{~W}$ is approximately 11.8; through laser nitration with $120 \mathrm{~W}$ is approximately 10 greater;

The increases in comparison with the quenched state of the steel X5CrNi18-10 is:

- after the value of the cavitation erosion resistance $R_{\text {a }}$ : by nitration with laser power $240 \mathrm{~W}$ is 1.9 times greater; by nitration with laser power $180 \mathrm{~W}$ is 1.8 times greater; by nitration with laser power $120 \mathrm{~W}$ is 1.7 times greater;

- after the values of mean depth erosion $M D E_{\text {max }}$ obtained after an exposure of 165 min are: after nitration with 180 $W$ is approximately 1.92 times greater; after nitration with $120 \mathrm{~W}$ is approximately 1.58 times greater.

The results of scanning electron microscopy, on the sectioned specimens, after 165 min of cavitation exposure, (fig.12a-12.c), are in excellent concordance with the previous presented observations. On one hand, they demonstrate the efficiency of the nitration treatment upon the improvement of the behavior to cavitation erosion and on the other hand, the influence of the laser beam power upon the thickness of the layer enriched in nitrogen (D1). From the figures it results that for great powers of the laser beams the thickness of the layer after cavitation exposure is greater (compare fig. 6a, 7a, 8a and 10a with 12a, 12b and $12 \mathrm{C}$ ).

The EDX analyzes of some micro volumes of the nitrated layer before and after the cavitation exposure (fig. 13) show that the cavitation erosion does not determine modification of the steel chemical composition.

\section{Conclusions}

The three tested nitration regimes applied to the steel X5CrNi18-10, as a result of the hardness realized, compared with those of the standard steel OH12NDL and those obtained through simply quenching the tested steel (maintained $25 \mathrm{~min}$ at $1050^{\circ} \mathrm{C}$ and sudden cooling in water), has at result a great improvement at cavitation erosion resistance. The thermochemical nitration does not have significant modifications of the chemical composition of the metal; it was done only a nitrogen enrichment of the superficial layer, with great effects upon the hardness. 
As can be seen in the figures of specimen section, during the experimental exposure to cavitation the erosion, the nitrated layers were not exceed.

The bigincreases of the resistance to cavitation erosion recommend this treatment for details subjected to intense cavitation erosion such as occur in hydro-mechanical equipment. The great problem remain the dimension of the detail and the complexity of the geometrical configuration. After our opinion the procedure can be easily applied to rings used for fixing the butterfly vanes, valves, seats of valves in pumping systems or irrigation.

\section{References}

1.FRANC, J.P., MICHEL, J.M. Fundamentals of Cavitation, Kluwer Academic Publishers, P.O.Box, 322, 3300 AH Dordrecht, The Netherlands, 2004

2.PATELLA, R.F., REBOUD, J.L., ARCHER, A., Cavitation damage measurement by 3D laser profilometry, Wear, vol.246, p. 59-67, 2000, 3.Huang, W.H., Chen, K.C., He, J.L., A study on the cavitation resistance of ion-nitrided steel, Wear, 252, pp. 459-466, 2002

4.BRUNN, B., LUDWIG, G., STOFFEL, B., The efect of gas diffusion of bubble dynamics, Cav03-GS-2-004, Fifth International symposium on cavitation (Cav2003), Osaka, Japan, 3-4 November, p.1-4, 2003

5.ESCALER, X., DUPONT, P., AVELLAN, F., Experimental investigation on forces due to vortex cavitation collapse for different materials, Wear, vol. 233-235, p.65-74, 1999

6.BORDEASU, I., MITELEA, I., LAZAR, I., MICU, L. M., KARANCSI, O., Cavitation Erosion Behaviour of Cooper Base Layers Deposited by HVOF Thermal Spraying, Rev. Chim. (Bucharest), 68, no. 12, 2017, p.2914-2918

7.LECOFFRE, Y., ARCHER, A., A method to evaluate cavitation erosion in valves, Third International symposium on Cavitation, Grenoble, France, 1998

8.MICU, L.M., LAZAR, I., CIRCIUMARU, A., BORDEASU, I., PIRVULESCU,L.D., HLUSCU, M., New results regarding cavitation behavior of polymers modified with anorganic substances coated on bronze surfaces, Mat. Plast. 55, no. 3, 2018, p. 460-463

9.GARCIA, R., HAMMITT, F.G., NYSTROM, R.E., Correlation of cavitation damage with other material and fluid properties, Erosion by Cavitation or Impingement, ASTM, STP 408 Atlantic City, New Jersey, U.S.A, 1960 10.HAMMITT, F.G., BHATT, N.R., Cavitation damage resistance of hardened steels, Univ. Michigan, pp. 1-36, 1970
11.YILBAS, B.S., ARIF, A. F. M., KARATAS, C., AKHATAR, S., ABDUL ALEEM, B.J., Laser nitriding of tool steel: Thermal stress analysis, International J ournal of Advanced Manufacturing Technology, 49(9), p. $1009-1018,2010$

12.KATONA, E.S., Eroziunea cavitationala a otelurilor inoxidabile cu transformare martensitica indirecta, Teza de doctorat, Timisoara, 2017 13.TOMLINSON, W.J., TALKS, M.G, Laser surface processing and the cavitation erosion of a $16 \mathrm{wt} \% \mathrm{Cr}$ white cast iron, Wear,vol. 139 , pp. 269-284, 1990

14.MICU, L.M., Comportarea la eroziune prin cavitape a opelurilor inoxidabile Duplex, Teza doctorat, Timisoara, Timisoara, 2017

15.SALCIANU, C.L., Curgere in vanele fluture si eroziunea prin cavitatie a componentelor din oteluri inoxidabile austenitice, Teza doctorat, Timisoara, 2017

16.***https://www.makeitfrom.com/material-properties/EN-1.4301X5CrNi18-10-Stainless-Steel

17.BORDEASU, I., MITELEA, I., SALCIANU, L., CRACIUNESCU, C. M., Cavitation Erosion Mechanisms of Solution Treated X5CrNi18-10 Stainless Steels, Journal of tribology-transactions of the ASME, Volume: 138, Issue: 3, 2016, Article Number: 031102, DOI: 10.1115/ 1.4032489

18.*** http://www.inoxmetalssr.ro/catalog/inox

19.MITELEA, I., GHERA, C., BORDEASU, I., CRACIUNESCU, C. M., Ultrasonic cavitation erosion of a duplex treated $16 \mathrm{MnCr} 5$ steel, INTERNATIONAL J OURNAL OF MATERIALS RESEARCH, Volume: 106 (4), p.391-397, 2015

20.MITELEA, I., MICU, L.M., BORDEASU, I., CRACIUNESCU, C. M.,Cavitation Erosion of Sensitized UNS S31803 Duplex Stainless Steels, J OURNAL OF MATERIALS ENGINEERING AND PERFORMANCE, 25(5), p.1939-1944, 2016

21.ANTON, I., Cavitatia, vol. I, Editura Academiei RSR, Bucuresti, 1984 22.BORDEASU, I., Eroziunea cavitationala a materialelor, Editura Politehnica Timisoara, 2006

23.ANTON, I., Cavitatia, vol. II, Editura Academiei RSR, Bucuresti, 1985

24.OANCA, 0,V., Tehnici de optimizare a rezistentei la eroziunea prin cavitatie a unor aliaje CuAINiFeMn destinate executiei elicelor navale, Teza de doctorat, Timisoara, 2014

$25 . * * *$ Standard method of vibratory cavitation erosion test, ASTM, Standard G32-2010

Manuscript received: 20.07 .2018 